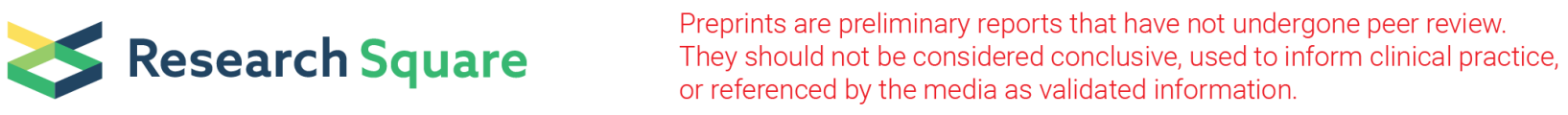

\title{
Nursing Care Case Report of Patient of COVID-19
}

\section{Saniye Bilgin}

Republic of Turkey Ministry of Health: Turkiye Cumhuriyeti Saglik Bakanligi

Hilal Uysal ( $\sim$ hilaluysal@gmail.com )

ISTANBUL UNIVERSITY CERRAHPASA FLORENCE NIGHTINGALE NURSING FACULTY https://orcid.org/0000-0003-32117011

\section{Report}

Keywords: Health, nursing care, nursing process, nursing diagnosis, COVID-19 Virus Infection.

Posted Date: July 14th, 2021

DOI: https://doi.org/10.21203/rs.3.rs-693131/v1

License: (c) (1) This work is licensed under a Creative Commons Attribution 4.0 International License. Read Full License 


\section{Abstract}

The functional health patterns model and nursing care process based on the nursing diagnosis of an individual with the diagnosis of COVID-19 were reviewed in this case report. An individual with the diagnosis of COVID-19 was evaluated in line with the functional health patterns (FHP) model, nursing diagnosis was made and a nursing care process was implemented in this case report. The data were collected by the researcher through observation and evaluation. N.B. was evaluated in line with the FHP nursing care model on 7 to 14 August 2020, and nursing procedures were implemented for these diagnoses and the results were evaluated.

\section{Introduction}

Coronaviruses (COV) are a large family of viruses that are common in the society, such as colds, and can cause self-limiting mild infections up to more serious infection pictures like Middle East Respiratory Syndrome (MERS) and Severe Acute Respiratory Syndrome (SARS) [1]. In December 2019, a pneumonia outbreak associated with a novel coronavirus called SARS-CoV-2 was reported in Wuhan in the China's Hubei province. The World Health Organization named the disease caused by the new coronavirus as Coronavirus Disease 2019 (COVID-19) on February 12, 2020. The disease has become a complicated and rapidly evolving global problem with the gradually increasing COVID-19 cases reported in countries around the world as of March 9, 2020 [2]. The first COVID-19 case in our country was confirmed on March 11, 2020. In the following period, the number of cases continued to increase both in the world and in our country [1].

The disease mainly indicates that COVID-19 is transmitted from symptomatic people to individuals through droplets, direct contact with infected people, or contact with objects and surfaces [3]. COVID-19 infection is transmitted by contact with other people's hands to droplets emitted by sick individuals through coughing, sneezing and rubbing their hands on the mucous membranes of the mouth, nose or eyes. Incubation time usually ranges from 2 to 14 days [1]. According to available data, the risk of contagion when symptoms occur is higher than the risk of contagion in the later stages in patients [3].

Respiratory symptoms, fever, cough, and dyspnea are the common symptoms of infection. Symptoms such as headache, sore throat, nasal discharge, muscle and joint pain, excessive fatigue, newly emerged loss of sense of smell and taste and diarrhea can also be observed. Although the disease can be asymptomatic, severe cases of pneumonia, severe acute respiratory infection, renal failure and even death may occur [1].

The measures required to reduce the transmission of COVID-19 are specified in the 72nd coronavirus report of World Health Organization (WHO). According to this report, social and physical distancing measures are among the necessary measures, including individual and environmental measures, detection and isolation of cases, quarantine, prevention of crowded gatherings, international travel measures, vaccines and treatments. Social and physical distancing measures aim to slow the spread of the disease by stopping the transmission chains of COVID-19 and preventing the appearance of new ones. These measures promote virtual and social connections for families and communities, while reducing physical distance (at least one meter) between people and contact with contaminated surfaces. General public measures include flexible working, remote working, distance learning, reduction and prevention of crowding, closure of unnecessary facilities and services, and home stay measures. All of these measures should be followed together with individual precautions, such as frequent hand washing rules and compliance with the rules to be considered when coughing against COVID-19 [4].

Not only physical but also psychological care and support are provided in the fight against the new coronavirus through nursing care, as in the past infectious diseases. Throughout the pandemic, nurses did not leave patients alone and often continue to be with them even in the last moments of their lives. Even in the post-mortem period, nursing care continues by making preparations until the patient's transport, providing transport procedures appropriately and supporting the mourning process of their relatives [5].

In this case, an individual diagnosed with COVID-19 was evaluated according to Marjory Gordon's Functional Health Patterns (FHP) Nursing Care Model [6, 7]. The patient was diagnosed with NANDA nursing [8,9], and nursing process care was 
administered. This model, which considers the individual as a holistic bio-psycho-social aspect, examines the needs of individuals in 11 functional areas. These areas allow systematic and standardized data collection and analysis of data in line with nursing philosophy. Gordon's functional health patterns are a process described to be used by nurses to make a more comprehensive assessment in patient care practices and to administer the nursing process $[7,10]$.

\section{Case Report}

N.B. is a 32-year-old female patient, a teacher, and married having a child. N.B. has no history of a chronic disease and surgery related to the respiratory system before her current disease. She has no history of known food and drug allergy, a past operation and any medication she takes.

N.B. has no known illness and a polymerase chain reaction (PCR) test was conducted on August 5, 2020 as a result of COVID-19 filiation studies due to contact with an individual with COVID-19 infection. She admitted in emergency outpatient department on August 7, 2020 upon positive polymerase chain reaction test, having throat ache, fatigue, tiredness, dry cough and high fever $\left(38.8^{\circ} \mathrm{C}\right)$ persisting for four days. The patient, who has no history of comorbid or chronic diseases, does not smoke and does not use alcohol or any substance. The patient who contacted an individual with COVID-19, has never been hospitalized and has no familial risk factors. The computed tomography (CT) report of the patient was evaluated, found to be compatible with COVID-19 pneumonia, and hospitalized in the COVID-19 inpatient department. The patient's overall condition is good, conscious and cooperating. Vital signs of N.B. are stable and she is monitored under spontaneous breathing.

Current medications of N.B.: She was started on Favimol $200 \mathrm{mg} \mathrm{2 \times 8} \mathrm{tablet} \mathrm{(oral)} \mathrm{treatment} \mathrm{on} \mathrm{the} \mathrm{first} \mathrm{day.} \mathrm{She} \mathrm{was} \mathrm{started}$ on Favimol 200 mg 3x2 tablet, Vogast 30 mg 1x1 (oral), Enox 4000 Anti-xa IU/0.4 ml 1x1 (subcutaneous), Lansopral 30 mg $1 \times 1$, Isotonic Sodium Chloride Solution $1000 \mathrm{ml} 1 \times 1$ (IV) as of the second day of treatment.

Medical diagnosis of N.B: COVID-19 disease.

\section{EVALUATION OF THE CASE ACCORDING TO THE FUNCTIONAL HEALTH PATTERN MODEL}

\section{Perception of health - Management of health}

N.B. stated that her condition was moderate, did not have regular health checks, dose exercise occasionally, and has no history of smoking and alcohol. Body mass index (BMI) was calculated $26.4 \mathrm{~kg} / \mathrm{m}^{2}$. N.B. has severe back pain, joint pain, headache as well as sore throat and chest pain secondary to cough. She shows incompatibility with the diet and fluid plan. She cannot do her works that takes effort, shows extreme tiredness, weakness and an increased respiratory rate when going to the toilet.

\section{Nursing diagnosis 1: Acute Pain (NANDA Field 12: Comfort, Class 2: Physical Comfort)}

Purpose of nursing care: It is the patient's experience of less than 3 pain according to the 0 to 10 pain scale and verbal and non-verbal expression of his/her pain.

\section{Interventions:}

- Assessment of the location, severity and nature of pain; determining its level according to the pain scale and monitoring it at intervals,

- Investigating the factors that reduce and increase pain and eliminating the factors that increase pain (light, stress, noise, position disorder),

- Administering the appropriate analgesic treatment ordered by the physician and evaluating the results,

- If not contraindicated, applying non-pharmacological methods for pain control (back massage, darkness, muscle relaxation exercises, position change, etc.) [11], 
- Keeping the patient away from situations causing stress and discomfort,

- Ensuring the patient's bed rest,

- Informing the patient about the causes of the pain, its occurrence due to the disease and when it will disappear,

- Ensuring the patient's participation in care with a calm and supportive approach,

- Explaining the importance of breathing exercises in the treatment of COVID-19, and planning exercise in 3 periods per day (puckered lip breathing, diaphragmatic breathing, deep breathing exercises) [12].

Nursing diagnosis 2: Ineffective health management (NANDA Field 1: Improving Health, Class 2: Management of Health)

Purpose of nursing care: It is ensuring that the patient maintains his/her health effectively, recognizes complications early, prevents from COVID-19 infection and maintains his/her own care effectively by knowing the risks of transmission.

Interventions:

- Providing information on the COVID-19 infection and how to reduce the risk factors that worsen its effects,

- Supporting and encouraging every correct behavior for the health of the individual,

- Informing the patient and his/her family about isolation methods to prevent COVID-19 transmission.

- Explaining the importance that the patient and those contact with the patient should wear all protective equipment completely and completely [13]

- Providing information on the importance of ensuring full social isolation, and informing the patient and his/her family as necessary to minimize the risk of COVID-19 infection transmission [14].

\section{Nutrition-Metabolic Status}

N.B. stated that she had fatigue, loss of appetite and nausea during the disease. N.B. further stated that her cough induced sore throat and sensitivity in the throat reduced the desire to eat, experienced dry mouth because she was breathing through the mouth due to nasal congestion, and that these are the factors for decreased nutrition. She had complaints of excessive sweating and fatigue due to high fever ranging $38.5^{\circ} \mathrm{C}$ to $39.1^{\circ} \mathrm{C}$.

Nursing diagnosis 3: Malnutrition: Nutrition less than body requirement (NANDA Field 2: Nutrition, Class 1: Swallowing)

Purpose of nursing care: It is the patient's understanding of the importance of nutrition during the COVID-19 infection, complying with the planned diet, maintaining a normal weight and not losing weight.

Interventions:

- Monitoring the weight of the patient and evaluating the food taken,

- Explaining that a weak immune system increases susceptibility to infections (Turkish Academy of Sciences, 2020b),

- Explaining the relationship of strong immune system with food in COVID-19 infection [15, 16],

- Providing information about the importance of good nutrition in creating a strong immune system in COVID-19 infection [17],

- Supporting and encouraging the adoption of appropriate nutrition in the fight against COVID-19 infection,

- Planning a daily diet rich for antioxidants, vitamins, vitamin D, omega 3, zinc, pre- and probiotics known to have positive effects on the immune system $[17,18]$,

- Explaining the importance of patient's attention to fluid intake and encouraging them to drink 8 to 10 glasses of water daily,

- Foods consumed should not be too cold, too hot, too bitter or too spicy in order to prevent throat sensitivity, 
- Not doing exercises that require excessive effort before meals and, if possible, resting before meals to prevent anorexia secondary to fatigue,

- Ensuring oral hygiene before and after meals and to encourage oral care,

- Ensuring the consumption of soft and liquid foods to prevent sore throat caused by cough,

- Informing patients about the importance of disposable plates, spoons and forks due to the risk of COVID-19 transmission (19).

Nursing diagnosis 4: Fluid volume deficiency risk (NANDA Field 2: Nutrition, Class 5: Hydration)

Purpose of nursing care: It is moist mucous membranes to show fluid balance, good skin turgor, stable vital signs and normal capillary filling.

\section{Interventions:}

- Following up the intake and output balance and determining the fluid amount that the patient should take,

- Informing the patient about the importance of adequate fluid consumption,

- Evaluating dehydration findings (headache, cracked lips, dry skin, dark urine color, dry mouth, dry and sticky mouth, decreased need for urination, muscle cramps, thirst, dizziness),

- Informing about consuming liquids with diuretic effects such as coffee, tea, grapefruit juice carefully [20,21],

- Determining fluids lost by vomiting, diarrhea, hyperthermia,

- Assessing the patient's skin turgor,

- Monitoring vital signs due to the risk of developing symptoms such as hypotension and tachycardia,

- Administering an antiemetic therapy suitable to the patient in case of nausea and vomiting,

- And monitoring the patient's body temperature.

\section{Nursing diagnosis 5: Hyperthermia (NANDA Field 11: Safety/Protection Class 6: Thermoregulation)}

Purpose of nursing care: It is to keep the body temperature within normal limits.

\section{Interventions:}

- Monitoring the patient's body temperature at frequent intervals,

- Monitoring the fluid intake and urine output,

- Regulating the room temperature and environmental factors,

- Ensuring that the clothes are comfortable, thin and cotton,

- Administering drug therapy under the control of the physician when the metabolic rate and oxygen consumption will increase if the patient has tremor,

- Supporting the patient's fluid intake [18],

- Monitoring vital signs at regular intervals,

- Cold application to lower body temperature,

- Explaining to patients that they should change her clothes and bed linen after sweating and put dirty items in a special bag and close it,

- Administering antipyretic drugs according to the physician's order and monitoring the sweating level following antipyretic treatment.

Nursing diagnosis 6: Deterioration of the Oral Mucous Membrane (NANDA Field 11: Safety/Protection, Class 2: Physical Injury) 
Purpose of nursing care: It is ensuring oral membrane integrity and moisture, maintaining adequate nutrition and fluid intake and ensuring optimal oral hygiene.

\section{Interventions:}

- Evaluating the oral care habits of the patient and explaining the importance of oral care at regular intervals and following it up,

- Evaluating the oral cavity in terms of bad breath, lesions, pain or bleeding,

- Applying moisturizing cream to lips every 2 hours and/or as needed [10].

- It is informing the patient about feeding with small and frequent meals and not eating very hot and very cold foods and avoiding hard-shelled foods in order not to increase oral irritation.

Nursing diagnosis 7: Nausea-Vomiting (NANDA Field 12: Comfort, Class 1: Physical Comfort)

Purpose of nursing care: It is minimizing nausea and vomiting and to ensure that the patient eats normally.

\section{Interventions:}

- Evaluation of factors and potential risks that may play a role in nausea and vomiting,

- Monitoring the intake and output balance and evaluating the vital signs and dehydration of the patient,

- Administering antiemetic suitable for the patient when needed,

- Planning a less and frequent diet,

- Explaining the importance of slow consumption of fluids to prevent nausea and to recommend a liquid-weighted and soft diet to reduce nausea,

- Stating that very hot foods should not be preferred as they may increase the feeling of nausea,

- Informing the patient about that he/she has nausea due to the infection and when it will end,

- Teaching the patient to use deep and slow breathing, visualization, meditation and relaxation techniques such as yoga when the nausea reflex occurs,

- Menthol sugar can be eaten to reduce nausea,

- Choosing loose and non-tight clothing,

- Explaining that nausea and vomiting are caused by COVID-19 infection [22,23].

\section{Defecation}

The patient stated that her normal defecation was once a day, but now she has defecated 7-8 times a day. The patient's bowel sounds were determined as $15 / \mathrm{min}$. N.B. stated that her stool is soft and fluid.

Nursing diagnosis 8: Diarrhea (NANDA Field 3: Defecation/Gas Exchange, Class 2: Gastrointestinal Function)

Purpose of nursing care: It is to ensure that the feces are in the amount and consistency of normal defecation.

\section{Interventions:}

- The onset of diarrhea and the number, content, amount and color of defecation during the day,

- Monitoring the intake-output balance and weight,

- Observing the vital signs,

- Monitoring the patient for signs of dehydration due to fluid loss [24].

- Increasing liquid food intake (soup, fruit juice, etc.), 
- Avoiding foods prepared without cooking and planning a diet with a restricted fiber ratio for the patient,

- Ensuring that liquid foods are not consumed too hot and too cold,

- Ensuring that light and easy-to-digest foods are consumed at short intervals,

- Evaluation of the presence of abdominal pain,

- Informing the patient about the importance of the personalized toilet and toilet hygiene in order to prevent contamination with stool $[25,26]$,

- Informing the patient about the importance of hand washing $[17,27,28]$.

\section{Activity-Exercise}

N.B stated that her energy was insufficient and she was inadequate to perform daily life activities due to weakness, fatigue and intense back and joint pain. She also stated that she was out of breath during the activity and had increased pain in her legs and heels.

Nursing diagnosis 9: Activity Intolerance (NANDA Field 4: Activity/Rest, Class 4: Cardiovascular/Pulmonary Responses)

Purpose of nursing care: Enabling the patient to continue daily life activities without pain, dyspnea and fatigue.

\section{Interventions:}

- Determining the patient's tolerance to exercise and to what extent she is able to do daily living activities,

- Monitoring the cardiorespiratory response after activities (tachypnea, tachycardia, sweating, dyspnea, pale/pallor),

- Explaining the importance of regular physical activity and exercise for preventing chronic and metabolic diseases and ensuring psychological well-being,

- Encouraging the patient to use controlled breathing techniques (puckered lip and diaphragmatic breathing) during emotional and physical stress and during excessive activity [27,29],

- Determining appropriate exercise plans such as knee-elbow exercises, yoga, stretching that can be done at home without using any equipment $[30,31]$,

- Teaching simple practices to support activities such as standing while talking on the phone, taking steps in the room of isolation, doing arm and leg exercises where she sits in order to prevent immobility and regain muscle strength,

- Informing the patient that activity and exercise are important to increase physical activity, stay healthy and increase body immunity,

- Adopting regular sleep and eating habits in order to protect and maintain sufficient energy resources and following them up,

- Explaining to the patient that the activity should be stopped when she feels chest pain, dyspnea, dizziness or fatigue,

- Determining sufficient time between exercises for the patient to rest and encouraging the patient for activity,

- Eliminating the factors that prevent the patient's energy from being released,

- Teaching energy conservation techniques (such as putting things in easily accessible places, pushing instead of pulling, sliding instead of lifting),

- Supporting the patient in carrying out activities when needed,

- Avoiding clothes that may affect blood flow, breathing rhythm and physical comfort, and choosing appropriate clothes that provide physical comfort,

- Encouraging to increase the activity level, providing emotional support.

- To regain muscle strength by doing exercises such as airing the isolation areas frequently, walking in the room, doing arm and leg exercises while sitting, and squatting while standing [12,32,33]. 


\section{Sleep-Rest}

N.B. stated that she could not wake up in the morning rested and woke up frequently at night with sweating secondary to severe cough, headache and high fever. The need for frequent urination at night secondary to diarrhea disrupts the sleep pattern of a patient.

Nursing diagnosis 10: Disruption to sleep pattern (NANDA Field 4: Activity/Rest, Class 1: Sleep/Rest)

Purpose of nursing care: It is providing adequate and quality sleep and feeling rested in the morning.

\section{Interventions:}

- Determining the sleep habits of the patient,

- Explaining that maintaining sleep pattern will accelerate recovery of the COVID-19 disease and its importance to increase immunity [34,35],

- Providing a quiet and calm environment while the patient is sleeping,

- Teaching the application of relaxation therapy (trying to focus on good thoughts in a calm environment), cognitive therapy (avoiding guiding the brain with false thoughts such as thinking that they will not be able to fall asleep in bed) to make it easier to fall asleep,

- Evaluating the patient in terms of individual, environmental and treatment factors during sleep hours [32,36],

- Determining the resting hours by considering the patient's nutrition and medication hours,

- Supporting the patient to express her fears and concerns about adaptation to the environment,

- Eliminating factors that prevent falling asleep such as hyperthermia and pain,

- Avoiding stimulating mental activity right before bedtime (for example, watching action movies, encouraging speech), applying relaxing events such as warm shower, massage and touch, relaxation exercises, listening to music to ensure comfort,

- Ensuring that the patient wears comfortable and cotton clothes,

- Informing patients that they should not drink stimulants such as caffeine $[28,37,38]$.

\section{Cognitive-Perceptual State}

N.B. has a time, place and person orientation. Her Glasgow Coma Scale is 15. She stated that she did not experience any problem in her hearing, feeling and touch senses, but there was a change in the taste and smell senses. N.B. stated that she does not know much about the new disease COVID-19 and she is very scared. She said that she did not know exactly how to cope with the disease and the isolation rules.

Nursing diagnosis 11: Lack of information (NANDA Field 5: Perception/Comprehension Class 4: Comprehension)

Purpose of nursing care: It is the elimination of information deficiencies about the disease.

\section{Interventions:}

- Evaluation of the patient's level of knowledge about COVID-19,

- Providing information about known false and incomplete information about COVID-19 disease,

- Informing about isolation rules (using private toilet and bathroom at home, wearing masks, airing the room properly, using personal items, hand hygiene, separating masks and other garbage, etc.),

- Encouraging the patient to ask questions,

- Reevaluating the patient's level of knowledge after providing necessary information $[39,40]$. 


\section{Self-Perception-Self-Concept}

N.B. stated that she generally had death anxiety. She expressed that she had a young child of sixteen months and was worried that she was away from his/her. She said that she was feeling tired and bored with isolation. She said that she lost hope because the disease had no cure and vaccine.

Nursing diagnosis 12: Death Anxiety (NANDA Field 9: Coping/Stress Tolerance, Class 2: Coping)

Purpose of nursing care: It is taking the responsibility of active participation in treatment and achieving effective coping methods by reducing anxiety and relaxing the patient.

\section{Interventions:}

- Evaluating the isolated patient in terms of behavior and situation related to the presence of fear of death anxiety and questioning whether the coping methods used in the past were effective, and, if ineffective, teaching effective coping methods,

- Informing the patient about the procedures related to the isolation and treatment process,

- Identifying situations that increase the patient's anxiety and minimizing these stressors (41).

- In order to teach appropriate coping methods, an empathetic approach should be adopted and the patient should be encouraged to ask questions and express their feelings to develop a relationship based on trust,

- Ensuring a simple and honest communication with the patient based on the information that is consistent and heard and understood by the patient

- Explaining the reasons for isolation to the patient to ensure his/her own control,

- Application of relaxation methods such as muscle stretching, deep breathing exercises, massage and creating a calm and quiet and relaxing environment [42].

Nursing diagnosis 13: Fatigue (NANDA Field 4: Activity/Rest Class 3: Energy Balance)

Purpose of nursing care: It is minimizing the fatigue level of the patient.

\section{Interventions:}

- Determining the factors that cause fatigue,

- Evaluation of the patient's fatigue level and perception,

- Determining the factors that increase and decrease fatigue,

- Supporting the patient while performing daily life activities,

- Preventing unnecessary energy consumption and teaching energy conservation techniques (such as putting things in easily accessible places, pushing instead of pulling, sliding instead of lifting),

- Regular rest planning during the day to reduce the patient's fatigue.

Nursing diagnosis 14: Hopelessness (NANDA Field 6: Self-Perception, Class 1: Self-Concept)

Purpose of nursing care: It is eliminating the patient's hopeless situation and enabling the patient to see life positively and to express his/her positive thoughts about the future.

\section{Interventions:}

- Determining the reasons that make the patient feel hopeless,

- Encouraging the patient to express his/her feelings and thoughts that make his/her feel negative,

- Encouraging the patient for effective participation in terms of complying with the treatment, 
- Positive feedback for participation in care,

- Strengthening the patient's self-confidence and competencies,

- Strengthening the role of the patient according to his/her values and life satisfaction for the purpose of life,

- Informing the patient in general about the COVID-19 treatment process,

- Stating that the COVID-19 disease is a global problem despite the patient's reaction against the disease and explaining the issues that the patient is curious about,

- Disclosure of the correct information about the disease,

- Providing a realistic perspective to the patient about the treatment process and condition while informing him/her.

\section{Role-Relationship}

N.B. stated that he lives with her husband and child and that they have good familial relations. She said that she was uncomfortable because she could not fulfill her motherhood duty due to droplet and respiratory isolation because of the COVID-19 disease. She expressed regret that she could not meet with her family and relatives.

Nursing diagnosis 15: Social Isolation (NANDA Field 12: Comfort, Class 3: Social Comfort)

Purpose of nursing care: It is explaining the importance of isolation and minimizing the feeling of loneliness during the disease.

\section{Interventions:}

- Explaining the importance of social isolation in reducing infection in COVID-19 disease with a high rate of infection spread,

- Determining the methods to communicate with the family during the day in order to prevent the patient from feeling lonely (such as video conversation by means of technological devices),

- Providing the necessary information to the patient about the infection process,

- Supporting the patient for verbal communication,

- Observing the patient in situations such as anger, nervousness, anxiety

- Ensuring that anxiety and stress are minimized $[26,43]$.

Nursing diagnosis 16: Ineffective Role Performance (NANDA Field 7: Role Relationships, Class 3: Role Performance)

Purpose of nursing care: It is preventing the individual from feeling inadequate by supporting his/her role performance.

\section{Interventions:}

- Determining the role of the patient in the family,

- Determining the factors that cause deficiencies in the individual's role performance,

- The patient should be encouraged to express his/her feelings and thoughts and to develop alternative adaptive coping strategies (breathing, relaxation exercises, positive thinking, stopping thinking),

- Explaining that the situation is curable and temporary,

- Providing a suitable environment for familial communication,

- Providing information to family members about the process [44].

Nursing diagnosis 17: Interruption of family processes (NANDA Field 7: Role Relationships, Class 2: Family Relations)

Purpose of nursing care: It is the positive adaptation of family members to this change experienced due to disease. 


\section{Interventions:}

- Determining the characteristics of the family (family values, the role of the patient in the family, support strengths of the family, health habits, etc.),

- Determining the developmental stages of the family (marriage process, time of having a baby, illness, death, etc.)

- Identifying the coping methods used against short-term or long-term stress, defining the coping strategies developed by family members in response to the pandemic (adaptive, maladaptive), and supporting the family to develop alternative adaptive coping strategies for the future (breathing, relaxation exercises, thinking positive, stopping thinking, etc.) $[45,46,43]$,

- Teaching the patient effective coping methods,

- Informing the patient about the COVID-19 disease process,

- Using communication resources (telephone, PC, etc.) to communicate with the patient's family, psychosocially supporting family members who are in quarantine due to the risk of being infected with COVID-19 disease, enabling them to communicate with other family members via e-mail, social media, video and telephone and encouraging them to express their feelings in different ways (writing, reading, painting, etc.),

- Providing frequent and regular remote communication in order to prevent the patient from feeling himself/herself alone,

- Expressing the feelings of anger, stress and fear occurred in the family after the disease and providing support.

\section{Sexuality-Reproductive Form}

The patient expressed that there was no problem in her sexual life before COVID-19, and that she took a break from her sexual life due to isolation.

\section{Coping-Stress Tolerance}

N.B. expressed that she normally has a calm nature, but is experiencing fear and stress because she is currently fighting a disease that has no definitive treatment. The patient also explained that her fear was exhausting her and she had difficulty coping with it.

Nursing diagnosis 18: Ineffective individual coping (NANDA Field 9: Coping/Stress Tolerance, Class 2: Coping reactions)

Purpose of nursing care: Showing positive coping skills.

\section{Interventions:}

- Evaluation of positive and negative coping methods,

- Discussing effective coping methods and helping to use them,

- Ensuring active participation in treatment and care.

\section{Belief-Values Form}

The patient stated that communication with his family and visits of relatives were very important for her, but she was sad that no visits are allowed due to the isolation because of illness, and she was especially worried about her 16-month-old baby who was in the developmental period. The patient stated that she always prayed and continued to pray during this process, and that this situation was not contrary to her religious beliefs.

\section{CASE ANALYSIS}


For this case, a care plan was prepared and implemented using Marjory Gordon's Functional Health Patterns Nursing Care Model $[5,6]$ and NANDA nursing diagnoses $[7,8]$ to solve the problems of the patient diagnosed with COVID-19. Respiratory symptoms, fever, cough, and dyspnea are common signs of infection in patients with the diagnosis of COVID-19. Symptoms such as headache, sore throat, nasal discharge, muscle and joint pain, excessive fatigue, newly emerged loss of sense of smell and taste and diarrhea can also be observed. Although the disease can be asymptomatic, severe cases of pneumonia, severe acute respiratory infection, renal failure and even death may occur $[1,47,48]$.

Throughout the COVID-19 disease process, N.B. was followed up for 48 hours at the clinic and then at home. During this period, the patient was taken into isolation in a separate room and started on COVID-19 treatment. Throughout the disease process, N.B. was followed up for the diagnoses of "acute pain, ineffective health management, malnutrition: nutrition less than body needs, risk of fluid volume deficiency, hyperthermia, disorder in the oral mucous membrane, diarrhea, activity intolerance, disturbed sleep pattern, knowledge deficit, nausea-vomiting, death anxiety, tiredness, despair, social isolation, ineffective role performance, interruption of family processes and ineffective individual coping" according to her symptoms and findings.

N.B. verbally stated that her persistent pains decreased after the nursing care administered for the diagnosis of "acute pain". A quiet, calm and dark environment was prepared for the patient's headache. Analgesic treatment was administered when N.B.'s recurrent and persistent pains recurred, and the patient was taken to bed rest. The nursing care of the patient was supported by massage and practical breathing exercises. As a result of all the nursing interventions, the patient reported the pain as Visual Analogue Scale (VAS) 2/3 during this period, which was previously VAS 7/9, and the pain decreased.

Measures were taken for droplet isolation for the diagnosis of "ineffective health management". A hygienic and safe environment was prepared in a special room for the patient. In order to minimize the risk of social isolation and infection transmission, both the patient and her family were given the necessary training. As a result of nursing interventions, N.B. and her family have adapted to the measures taken for COVID-19 and said they have learned through training on what to watch out for against COVID-19.

After the nursing diagnosis of "malnutrition, less than body requirement", N.B. was trained about the importance of the strong immune system's relationship with food in COVID-19 infection and was encouraged to apply the diet. A daily diet plan rich for antioxidants, vitamins (B, C, D vitamins), omega 3, zinc, pre- and probiotics was implemented for N.B. Because of the loss of appetite of N.B, vitamins C, D and zinc supplements were given for immunity. N.B. adapted to the trainings given on the diet in terms of fluid intake (8 to 10 glasses of water a day). N.B. used disposable plates, spoons and forks due to the risk of contamination. N.B. kept her normal weight.

The patient's intake and output balance were monitored for the fluid volume deficiency risk" nursing intervention. N.B. Was evaluated for dehydration and symptoms such as headache, thirst, dark urine, and dry mouth were observed and the patient was supported for fluid intake. She was informed about consuming liquids with diuretic effects such as coffee, tea, grapefruit juice carefully. The patient's urine color (light yellow), thirst, and dry mouth symptoms returned to normal and fluid balance was restored.

For the nursing diagnosis of "hyperthermia", the patient's body temperature was monitored frequently. Fluid intake was supported by monitoring urine output and sweating. The temperature of the room was measured and ventilated frequently. Fatigue symptoms were observed due to hyperthermia and the patient was rested at these times. An increase in body temperature up to $39.1^{\circ} \mathrm{C}$ was noted and antipyretic drugs were administered by the physician order. Cold application was made during frequent high fever at nights. N.B., based on the training she received, changed her clothes and bed linen after sweating and put the dirty items in special bags and washed them in the washing machine at 60 degrees when necessary. As a result of all the nursing interventions, N.B.'s body temperature was reduced to $36.4^{\circ} \mathrm{C}$. Oral care practice habits of N.B. were evaluated for the nursing diagnosis of "Oral Mucous Membrane Deterioration". N.B. stated that she understood the importance of oral care during COVID-19 and did regular oral care. Oral membrane integrity and moistness was provided.

Page $12 / 20$ 
As a result of nursing interventions for the nursing diagnosis of "Nausea-Vomiting", N.B. stated the severity of her nausea and vomiting in terms of dehydration and her findings were followed up. In order to reduce the fatigue of the patient, the patient was recommended to eat less and often after each rest. The patient's daily fluid intake-output balance was supported, and her intake and weight were monitored. N.B. was weighed $70 \mathrm{~kg}$ on the first day of the disease. However, at the end of the day 4 , she was weighed $67 \mathrm{~kg}$. As a result of all the nursing interventions and training, she was weighed $70 \mathrm{~kg}$ on the last day of the disease. Relaxation techniques were taught to N.B., she adopted these methods and applied them when she had nausea. As a result of the nursing interventions, N.B. stated that she understood the importance of nutrition, loss of appetite disappeared, and deep and slow breathing exercise was an effective method in reducing nausea.

For the nursing diagnosis of "diarrhea", N.B.'s intake-output and weight were followed up and her fluid intake was supported. N.B. arranged her own diet according to the education on nutrition. Training was given on the importance of toilet hygiene and hand washing in COVID-19. N.B. stated that she understood the importance of toilet hygiene in order to prevent contamination risk. N.B. stated that her complaint of diarrhea was intense on the second day of her illness. After the nursing interventions, the complaint of diarrhea disappeared and the patient adapted to hygiene training.

According to the diagnosis of "activity intolerance", N.B.'s activity tolerance was evaluated. It was found that her skin was in normal color and temperature during the activity, but was dry. When not resting between activities, the patient was found to be out of breath and experienced also excessive sweating. The patient was trained on the harms of uncontrolled exercise, and instructed to terminate the exercise when she realizes that negative symptoms emerged during the exercise. It was found that the patient complied with these explanations and her tolerance to activity improved. N.B. practiced activities such as walking in the room, doing arm and leg exercises where she sat, not sitting and walking in the room while talking on the phone and knee-elbow exercises during the day in order to prevent immobility in the room. After nursing interventions, the patient experienced minimal pain (VAS 3/10) while performing daily life activities and her activity tolerance increased, but tachypnea and weakness continued when she exerted excessive effort.

For the nursing diagnosis of "Sleep Disruption", the patient was evaluated in terms of sleep habits and individual, environmental and treatment-related factors during sleep hours. N.B. understood the immunological importance of regular sleep during COVID-19 disease. A quiet and calm environment was provided to the patient during bedtime; N.B. stated that she understood training on avoidance of stimulating mental activity just before going to bed, warm milk, relaxation exercises, relaxation therapy to make it easier to fall asleep and practiced all of them. Medication times were adjusted, she was allowed to take a warm shower before going to bed at night, she was ensured not to sleep much during the day, night sleep was arranged, and N.B. was ensured to be rested in the mornings and get enough sleep after nursing interventions.

The knowledge level of the patient before and after the training was evaluated for the "Knowledge Deficit" nursing diagnosis. The patient realized that pre-training COVID-19 information was inadequate and inaccurate. N.B. was provided correct information and a general information (for example what is COVID-19, how to protect from COVID-19, what is the importance of isolation, the importance of adherence to treatment) was also provided considering the facts about COVID-19 disease. After nursing interventions, N.B. reached the required level of knowledge and stated that she left her fear behind.

At the onset of the disease N.B. stated that she had a high fear of death and the interventions for the "Death Anxiety" nursing diagnosis were applied. The patient's fear was identified and she was informed that she had the disease, but that did not mean that she would die. The patient was informed about the isolation process and was encouraged to ask questions. N.B. practiced coping methods including deep breathing exercises, massage, creating a calm and quiet and relaxing environment to leave her anxiety behind. After trainings, changes in the patient's general behavior and attitudes were observed, and her active participation in treatment was ensured. N.B. said that she left death anxiety behind as a result of the nursing interventions.

For the "fatigue" nursing diagnosis, the patient prevented unnecessary energy consumption through controlled energy consumption, and a rest plan was created during the day. After the nursing interventions, the patient's fatigue complaint decreased, but she stated that even if a little, the feeling of fatigue reappeared as a result of fast and heavy exercises. The 
reasons for the patient's hopelessness were evaluated for the "hopelessness" nursing diagnosis. Those who died from the COVID-19 disease around her, inadequate and incorrect information about the disease, and the fear of losing her family and especially her young son by thinking that she would infect him were determined as reasons that drove N.B. to hopelessness. A realistic perspective was presented to N.B. about the COVID-19 treatment process, general information was provided, and the level of hopelessness was minimized by correcting the wrong information she had. N.B. stated that she can think positively for the future as a result of the nursing interventions.

For the "social isolation" nursing diagnosis, the patient was informed about the importance and necessity of isolation. The patient's questions about the importance of isolation in reducing the risk of transmission in COVID-19 disease were answered. In order to prevent loneliness, a video call was established with the patient's family over the phone. N.B. stated that she understood the importance of social isolation and that the feeling of loneliness decreased with the communication provided.

For the "ineffective role performance" nursing diagnosis, the factors that cause ineffectiveness in N.B.'s role in the family and role performance were determined. The patient encouraged herself to express her feelings and thoughts, and she practiced positive thinking and stopping thinking, which are included in alternative adaptive coping strategies. N.B. stated that the situation is curable and temporary and that she understood the importance of the isolation process for herself and her family. Her reaction to the lack of role performance ended at the end of the nursing interventions.

The familial characteristics of the patient for the "interruption of family processes" nursing diagnosis were determined. Video conversation was made using technological devices to prevent interruption of family communication and to prevent the feeling of loneliness of the patient. As a result of nursing interventions, N.B. and her family members were ensured to adapt positively to this change experienced due to the disease.

Positive and negative coping methods of the patient were determined regarding the "ineffective individual coping" nursing diagnosis. The patient's active participation in the treatment was ensured by supporting coping methods to cope with the stress and anger that occur when she was inadequate.

\section{Discussion}

In COVID-19 cases, nurses should have sufficient knowledge and skills for patient follow-up, management of symptoms and evaluation of conclusions. Therefore, for the nursing care to be given to COVID-19 patients, detailed evaluation of the patient is important. N.B. was followed up in the clinic for 48 hours with the diagnosis of COVID-19 and at home after discharge, evaluated according to Gordon's FHP Model, and nursing care was given, interventions for the problems she experienced were planned and put into practice.

Respiratory symptoms, fever, cough, and dyspnea are the common symptoms of the COVID-19 disease. Symptoms such as headache, sore throat, nasal discharge, muscle and joint pain, excessive fatigue, newly emerged loss of sense of smell and taste and diarrhea can also be observed. Although the disease can be asymptomatic, severe cases of pneumonia, severe acute respiratory infection, renal failure and even death may occur [1]. Fever, cough, sore throat, muscle and joint pain, weakness, loss of sense of smell and taste, diarrhea and insomnia symptoms were also observed in N.B.

Caution should be exercised about the combined use of possible treatment options, the interactions and adverse effects of the drugs used for COVID-19 patients [49]. N.B. was started on favipiravir $2 \times 8$ on the first day and $2 \times 3200 \mathrm{mg}$ tablet on other 4 days for COVID-19. It was observed that the drug taken did not interact with other drugs and had toxic effects.

Pain may be the first symptom before the known symptoms of COVID-19 infection appear. The management of pain caused by COVID-19 infection, secondary pain due to complications of the disease, and chronic painful conditions should be reviewed during the pandemic. Additional factors such as anxiety, depression, social isolation and economic stress can make pain management difficult [50]. Pain is one of the first symptoms to occur in N.B. In addition to anxiety, social isolation and

Page $14 / 20$ 
fear of death, N.B.'s pain increased. Nursing interventions for anxiety and death anxiety were planned and put into practice. A decrease was observed in the pain level of the patient supported by coping methods.

Studies have shown that physical activity can improve the immune system as immune cells increase. In this context, it is recommended to increase the immune function that will protect the body against the virus through appropriate physical activity [51]. Due to COVID-19 infection, N.B.'s physical activity decreased. For the activity intolerance nursing diagnosis interventions, the patient was informed about the importance of physical activity on immunity and an exercise plan was created. N.B. increased her physical activity tolerance by practicing activities such as walking in the room, doing arm and leg exercises where she sat, not sitting and walking in the room while talking on the phone and knee-elbow exercises during the day in order to prevent immobility in the room.

Loss of appetite, malnutrition, dehydration caused by high fever and hypovolemic shock often concomitant to the main symptoms of COVID-19. Consuming adequate amounts of food and water is crucial to the treatment of COVID-19. Dynamically evaluating the patient, creating an individual treatment plan, monitoring the patient and making necessary changes are the main approaches in the treatment process of the disease [50]. N.B.'s daily fluid intake was evaluated and it was determined that she drank 3 to 4 glasses of water. She was informed about the importance of fluid intake in COVID-19, and N.B. increased her fluid intake by drinking 8 to 10 glasses of water a day. Dehydration and hypovolemic shock picture were not observed in N.B.

Diet is important for increasing body immunity in COVID-19 infection. A daily diet rich for antioxidants, vitamins, vitamin D, omega 3, zinc, pre- and probiotics known to have positive effects on the immune system is of great importance in the fight against COVID-19 [21,52]. N.B.'s diet was evaluated and a daily diet plan rich for antioxidants, vitamins (B, C, D vitamins), omega 3, zinc, pre- and probiotics was applied. Because of the loss of appetite of N.B, vitamins C, D and zinc supplements were given for immunity.

Patients in our country go through this process at home when hospitalization is not required, and isolated as one person in hospital rooms when hospitalization is required. Bed rest for just one week can cause serious muscle loss of up to $20 \%$ of the individual. Joint range of motion, stretching, and strengthening exercises can be included in the treatment plan during this period to increase muscle strength and endurance depending on the patient's condition [53]. N.B. exercised in the room in order to prevent muscle weakness during the infection process, reduced the rate of inactivity and increased the exercise duration every day. N.B. had no muscle loss.

Strengthening the social support networks by improving the coping skills of individuals and evaluating the stressful event can reduce the prolonged immune response induced by stress. Thus, both psychological and physiological well-being of the individual can be protected [54]. N.B. has put into practice adaptive coping strategies (breathing, relaxation exercises, positive thinking, stopping thinking) that are taught to eliminate the stress she experienced about the fear of COVID-19 infection and how to cope with the infection. N.B. struggled with the infection more effectively when her stress and fear were gone.

Routine changes in body posture such as half-sitting position, lateral position, and prone position should be made to reduce the work of respiratory muscles and conserve energy. In addition, abdominal breathing and puckered lip exercises, which are respiratory control techniques, should be used to expand the lower part of the chest and relieve breathing difficulties [21]. Correct breathing exercises were taught to N.B. to strengthen the respiratory muscles and prevent energy loss. During the day, N.B. Practiced the prone position and lip exercises, and it was observed that she was breathing effectively using her respiratory muscles.

\section{Conclusion}

In the COVID-19 epidemic, which the World Health Organization regards as a "pandemic", nurses are fighting at the forefront and will continue to fight at the forefront in the future. The World Health Organization stated that "nursing should be seen as a health investment in a country, not a cost" and "nurses are the backbone of the health system and are at the forefront of 
fighting COVID-19" and emphasized the importance of nursing care. Failure to follow the symptoms and pay attention to treatment and care in individuals with COVID-19 infection can be fatal. In this case, nurses play an important role in the care and treatment of COVID-19 patients.

As a conclusion, an individual diagnosed with COVID-19 was evaluated according to Gordon's Functional Health Patterns Model in this study and nursing care was administered besides NANDA nursing diagnoses. It was found to the care administered increased the patient's abilities and beliefs to fight COVID-19, provided psychological recovery, prevented fear of loneliness and COVID-19 infection, gained the ability to manage symptoms, increased coping tolerance and the trainings provided increased the patient's level of knowledge. In order for nurses to provide quality and holistic care to patients and their families, it is recommended to evaluate patients and administer nursing care with Gordon's Functional Health Patterns Model, which primarily deals with individuals in a bio-psycho-social dimension.

\section{Abbreviations}

BMI: Body Mass Index; CT: Computed Tomography; COV: Coronaviruses; COVID-19: Coronavirus Disease 2019; FHP :Functional Health Patterns; MERS: Middle East Respiratory Syndrome; PCR: Polymerase Chain Reaction; SARS: Severe Acute Respiratory Syndrome; WHO: World Health Organization; VAS: Visual Analogue Scale;

\section{Declarations}

Ethics approval and consent to participate: Ethical permission is not required for this article. Patient permission was obtained from the patient to write the article. Patient consent was obtained for care.

Consent for publication: Not applicable.

Availability of data and material: Please contact author for data requests.

Competing interests: The authors declare that they have no competing interests.

Funding: Not applicable.

Authors' contributions: $\mathrm{HU}$ and SB drafted the manuscript and organized the field survey. HU and SB wrote the manuscript. HU designed the study, supervised and reviewed the manuscript. HU and SB conceived and coordinated the whole work. The authors read and approved the final manuscript.

Acknowledgements: The authors would like to thank all the health professionals who supported in the clinic during the study and the patient who participated in the study.

\section{References}

1. Turkish Academy of Sciences. Republic of Turkey Ministry of Health, Guide for COVID-19 (SARS-CoV-2 Infection). Ankara:17 April 2020a. Accessed: 14.09.2020. Access

address: http://www.tuba.gov.tr/files/yayinlar/raporlar/Covid19\%20Raporu-revize.pdf

2. Zhou N, Zhang D, Wang W, Li X, Yang B, Song J, et al. A Novelcorona Virus From Patients With Pneumonia In China. New England Journal of Medicine 2020; 382: 727-733.

3.World Health Organization. WHO Coronavirus disease 2019 (COVID-19): situation report, 2020a:73. Accessed:14.08.2020. Access address: https://apps.who.int/iris/handle/10665/331686

4. World Health Organization. WHO Coronavirus disease 2019 (COVID-19): situation report, 2020:72. Accessed: 09. 08. 2020. Access address: https://apps.who.int/iris/handle/10665/331686

Page $16 / 20$ 
5. Kiyat I, Karaman S, İşcan Ataşen G, Elkan Kiyat Z. Nurses in The Fight Against The Novel Coronavirus (COVID-19). The Journal of Turkish Nurses Association 2020;1(1): 81-90.

6. Gordon M. Functional Health Patterns and Clinical Decision Making. In: Erdemir F. Yılmaz E. (Editors). Nursing Classification Systems, Their Use in Clinical Practice, Education, Research and Management Symposium Book. Ankara, 2003:87-93.

7. Enç N, Can G, Özcan Ş, Tülek Z, Uysal H. \& Alkan, H. Enç N. Can G. (Editors).. Internal Medicine Nursing Practice Student Education Module. 2nd Edition. İstanbul: Nobel Tıp Kitapevleri, 2017:7-140.

8. Herdman TH, Kamitsuru S. Nursing diagnoses, definitions and classification 2015-2017. 10th edition. UK: Wiley Blackwell. 2014.

9. Erdemir F. Nursing Diognasis in the Nursing Process. Carpentino, L, J. (Editors). Handbook of Nursing Diagnosis 13th Edition. Version. Istanbul, 2012: 376-378.

10. Uysal H, Karataş C. Nursing Care According to Functional Health Patterns in Chronic Renal Failure: A Case Report. Journal of Hacettepe University Faculty of Nursing 2017;4(2):49-61.

11. Bahar A, Buldak Ci. Nursing Management of COVID-19 Patients Who is in Intensive Care Unit. Journal of Health Science Yuksek Ihtisas University 2020;1:78-84.

12. Caner ZG, Ünal M, Apaydın Z, Dağ A, Okur Ş, Kara E, Bildik C. Covid-19 Disease and The Importance Of Home Exercises. Journal of Medical Sciences. Journal of Medical Sciences 2020;1(3):25-33.

13. Birlik Ö. Education of Patients and their Relatives About COVID-19: What Should Nurses Tell?. Journal of Biotechnology and Strategic Health 2020;4(2):78-88.

14. Republic of Turkey Ministry of Health. Leaflet of 14 Rules Against Coronavirus Risk Brochure. 2020a. [Internet]. Accessed: 07.08.2020.Access address: https://covid19.saglik.gov.tr/Eklenti/37663/0/covid1914kuralafis50x70pdf.pdf? _tag1=9D07F364A8E010A62B47454F4C96064EC1F94280

15. Eskici G. COVID-19 Pandemia: Nutrition Recommendations for Quarantine. Anatolian Clinic Journal of Medical Sciences 2020;25 (Special Issue 1):124-129.

16. Küçükcankurtaran S, Özdoğan Y. The Impact of the COVID-19 Pandemic on the Diet of Adults. Journal of Duzce University Health Sciences Institute, 2020. https://doi.org/10.33631/duzcesbed.754560

17. Türker A. Exercise and Diet During the Pandemic. 2020. [Internet] Accessed: 10.08.2020 Access address: https://www.researchgate.net/publication/345257958_Pandemide_Covid-19_Egzersiz_ve_Beslenme

18. World Health Organization Regional Office for the Eastern Mediterranean. Nutrition Advice For Adults During The COVID19 Outbreak. 2020. Accessed: 8.8.2020.Access address: http://www.emro.who.int/nutrition/nutrition-infocus/nutrition-advicefor-adults-during-the-covid-19-outbreak.html

19. Türken M, Köse Ş. COVID-19 Transmission and Prevention. The Journal of Tepecik Education and Research Hospital 2020;30:36-42.

20. Çelebi C. Nursing Care in Patients With Covid-19. Medical Journal of Aegean Clinics 2020;58(1):Supp:35-40.

21. Gök Metin Z. Physiopathology of COVID-19 and Holistic Nursing Approach. Journal of Hacettepe University Faculty of Nursing 2020;7 (Special Issue):15-24. 
22. Aygin D. Nausea and Vomiting. Journal of The Turkish Society Of Critical Care Nurses 2016;20(1):44-56.

23. Demirci NY. Approach to Nausea and Vomiting. 2020. [Internet]. Accessed: 09.08.2020 Access

address: https://www.solunum.org.tr/TusadData/Book/472/17620161213519_Bolum_18_Bulanti.pdf2

24. Eraydın Ş, Uçar KN. Nursing Care in Palliative Care According to Functional Health Patterns: Case Report. Turkish Journal of Science and Health 2020;1(2):94-107.

25. Republic of Turkey Ministry of Health. COVID-19 (SARS-CoV-2 Infection) (Science Committee Study) Infection Control and Isolation. 2020b. [Internet]. Accessed: 07.08.2020.Access address: https://covid19.saglik.gov.tr/TR-66338/enfeksiyonkontrolu-ve-izolasyon.html

26. Republic of Turkey Ministry of Health. COVID-19 (SARS-CoV-2 Infection) Contact Tracking, Outbreak Management, Home Patient Monitoring and Fillation. 2020c. [Internet]. Accessed 07.08.2020. Access

address: https://covid19.saglik.gov.tr/Eklenti/39605/0/covid19rehberitemaslitakibievdehastaizlemivefilyasyonpdf.pdf

27. Chekroud S, Gueorguieva R, Zheutlin AB, Paulus M, Krumholz HM, Krystal JH, Chekroud AM. Association Between Physical Exercise and Mental Health in 1.2 Million Individuals in the USA Between 2011 and 2015: A Cross-Sectional Study. The Lancet Psyhiatry 2018;5(9):739-746.

28. Karasu F, Doğan A. COVID -19 Patient and Nursing Care: Case Report. Van Health Sciences Journal 2020;13(COVID-19 special issue):53-58.

29. World Health Organization. Stay physically active during self-quarantine. 2020c. [Internet]. Accessed: 8.8.2020. Access address:https://www.euro.who.int/en/health-topics/health-emergencies/coronavirus-covid-19/technical-guidance/stayphysicallyactive-during-self-quarantine4

30. American College of Sports Medicine. Staying Active During COVID-19. 2020. [Internet]. Accessed August 9, 2020. Access address: https://www.exerciseismedicine.org/support_page.php/stories/?b=892

31. American Heart Association. Create a Circuit Home Workout Infographic. 2020. [Internet]. Accessed: August 9, 2020. Access address: https://www.heart.org/en/healthy-living/fitness/getting-active/create-a-circuit-home-workout

32. Güneş Z. Role and Strategies of Sleep Hygiene in Promoting Sleep Health. Archives Medical Review Journal 2018;27(2):188-198.

33. Beykümül A. Gülbaş G. Thoracic Diseases Pulmonary Rehabilitation in Patients with COVID-19. Eurasian Journal of Pulmonology, a publication of Turkish Respiratory Society 2020;22(4):104-109.

34. Akçay DB, Akıncı E, Özgen F, Aydın H, Güleç H, Demet MM. et al. Psychiatric Association of Turkey, Sleep and Disorders Study Unit. Recommendations for Sleep Hygiene in the Coronavirus Outbreak. European Psychiatric Association. 2020. [Internet]. Accessed August 9, 2020. Access address: https://www.psikiyatri.org.tr/TPDData/Uploads/files/UykuCOVID18042020.pdf

35. Turkish Society of Neurology. Sleep Disorders. 2020. [Internet]. Accessed:09.08.2020.Access address: https://www.noroloji.org.tr/menu/98/uyku-bozukluklari

36. Aslan R. Preventive Medicine and COVID-19. Lake District Monthly Journal of Economy and Culture 2020;89(8):53-57.

37. Republic of Turkey Ministry of Health. COVID-19 (SARS-CoV-2 Infection) Adult Patient Treatment. 2020d. [Internet]. Accessed 07.08.2020.

Accessaddress:https://covid19.saglik.gov.tr/Eklenti/39605/0/covid19rehberitemaslitakibievdehastaizlemivefilyasyonpdf.pdf 
38. Kenar L. Use of Personal Protective Equipment to Protect from COVID-19. Health Sciences University, Department of Medical Chemical Biological Radiation and Nuclear. 2020. [Internet]. Accessed: 15.08.2020. Ankara. Access address: http://www.sbu.edu.tr/FileFolder/Dosyalar/eb408a43/2020_6/covid19kisiselkoruyucuekipmankullanimi06b0bd54.pdf

39. Turkish Association of Psychiatry. COVID-19 and Mental Health. Methods That Can Be Applied to Cope With Tension. Science Ethics, Solidarity. 2020. [Internet]. Accessed: 10.08.2020 Access address: https://www.psikiyatri.org.tr/uploadFiles/2132020115258-gevsemebrosur.pdf

40. Fardin MA. COVID-19 and Anxiety: A Review of Psychological Impacts of Infectious Disease Outbreaks, Review Article. Archives of Clinical Infectious Diseases (COVID-19) (2020): e102779.

41. Kıyak E, Akdemir N. Nurse's Role İn Fibromyalgia Treatment. Journal Of Internal Medicine 2008;15(3):153-158.

42. Back A, Tulsky JA. Arnold RM. Communication skills in the age of COVID-19. Annals of Internal Medicine 2020;172(11):759-760.

43. Varcarolis EM, Halter MJ. Trauma interventions. Foundations of Psychiatric Mental Health Nursing: A Clinical Approach. (6th Edition), 2010: 527-625.

44. Oflaz F. The Psychological Impact of Disasters and Nursing Practice. Journal Of Cumhuriyet University School Of Nursing 2008;12(3):70-6.

45. Hossain MM. Current status of global research on novel coronavirus disease (COVID-19): a bibliometric analysis and knowledge mapping. F1000Research 2020;9(374).

46. İşsever H, Issever T, Oztan G. Epidemiology of COVID-19. Istanbul University Institute of Health Sciences Journal of Advanced Research in Health Sciences 2020;3(1):1-13.

47. Republic of Turkey, General Directorate of Public Hospitals. Information on Drugs to be Used in the Treatment of COVID19 (SARS-Cov2 Infection): Favipiravir 200 Mg Tablet. 2020. [Internet]. Department of Supply Planning, Stock and Logistics Management, Hospital Pharmacy Management Unit, 14 April 2020. Accessed 30.12.2020. Access address: https://covid19.saglik.gov.tr/Eklenti/37219/0/favipiravir-200-mg-tablet-guncelleme-tarihi-14042020pdf.pdf

48. Murat S, Yaksi E. COVID-19 Infection and Pain Management. Ayhan, F, F., Demirbağ, Kabayel, D. (Editors). COVID-19 Pandemic and Physical Medicine and Rehabilitation. 1. S1 is compressed. Ankara: Türkiye Klinikleri Journals 2020:70-4.

49. Nieman DC, Wentz LM. The Compelling Link Between Physical Activity And The Body's Defense System. Journal of Sport Health Sciences 2019;8(3):201-17.

50. Muslu M, Özçelik Örsü D. Nutritional Treatment and Its Importance During New Coronavirus (SARS-CoV-2/COVID-19) Pandemia. Bes Diy Der 2020;48(1):73-82.

51. Sarıkaya S. Cardiopulmonary Rehabilitation in COVID-19 Patients. Turkish Journal of Diabetes and Obesity 2020;2:177182.

52. Turkish Dietetic Association. (2020). [Internet]. Accessed:10.08.20. Access address: http://www.tdd.org.tr/index.php/duyurular/69-covid-19-beslenme-onerileri

53. Cansız A, Selvi Y, Şahin K. Psychological Stress and Immune System. Immunity, Nutrition and Lifestyle Report. Şahin, K. (Editors). Publications Of The Turkish Academy Of Sciences, Report No: 42, 2020:207-214. 
54. Karasu F. An Intensive Care Nurse in the Forefront of the Epidemic While Increasing Cases of Covid19: "HEROES IN FRONT-LINE". Journal Of The Turkısh Socıety Of Critıcal Care Nurse 2020;24(1):11-14. 